\title{
Chronic Kidney Disease in Tasmania: Protocol for a Data Linkage Study
}

Timothy Saunder ${ }^{1,2^{*}}$, BEng (Hons), BSc; Alex Kitsos ${ }^{1,2^{*}}$, B Phyt (Hons), MMedStat; Jan Radford ${ }^{3}$, MBBS, FRACGP; Kim Jose $^{4}$, PhD; Charlotte McKercher ${ }^{4}$, PhD; Rajesh Raj ${ }^{3,5}$, DM, FRACP, PhD; Nadine Wiggins ${ }^{6}$, BA, GradCertStats; Brian Stokes $^{6}$, BA; Matthew D Jose ${ }^{1,7,8}$, MBBS, FRACP, PhD

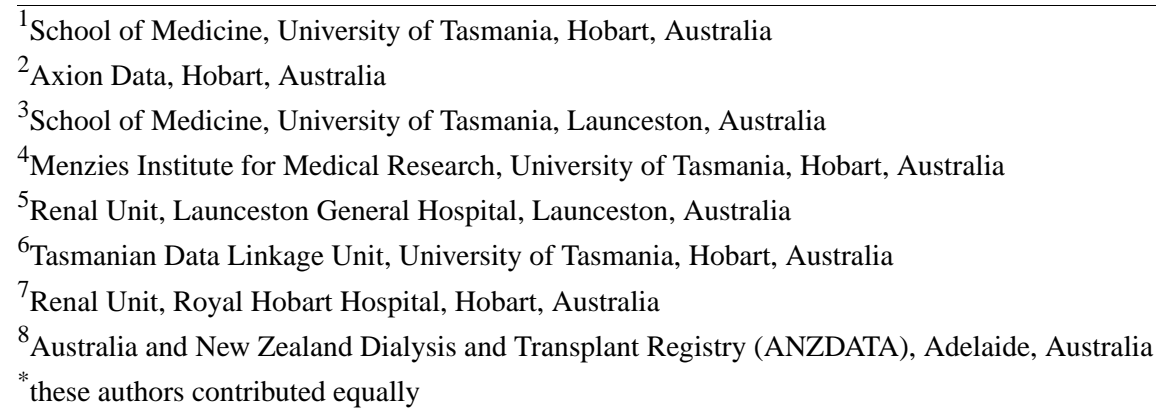

\section{Corresponding Author:}

Matthew D Jose, MBBS, FRACP, PhD

School of Medicine

University of Tasmania

17 Liverpool St

Hobart, 7000

Australia

Phone: 610362264660

Email: Matthew.Jose@utas.edu.au

\section{Abstract}

Background: Chronic kidney disease (CKD) is a significant and growing health burden globally. Tasmania has the highest state prevalence for non-Indigenous Australians and it has consistently had the lowest incidence and prevalence of dialysis in Australia.

Objective: To examine the gap between the high community prevalence of CKD in Tasmania and the low use of dialysis.

Methods: This is a retrospective cohort study using linked data from 5 health and 2 pathology data sets from the island state of Tasmania, Australia. The study population consists of any person (all ages including children) who had a blood measurement of creatinine with the included pathology providers between January 1, 2004, and December 31, 2017. This study population $(\mathrm{N}=460,737)$ includes within it a CKD cohort, which was detected via pathology or documentation of kidney replacement therapy (KRT; dialysis or kidney transplant). Kidney function (estimated glomerular filtration rate [eGFR]) was calculated using the Chronic Kidney Disease Epidemiology Collaboration (CKD-EPI) formula. Individuals with 2 measures of eGFR $<60 \mathrm{~mL} / \mathrm{min} / 1.73$ $\mathrm{m}^{2}$, at least 90 days apart, were identified as having CKD and were included in the CKD cohort. Individuals treated with dialysis or transplant were identified from the Australia and New Zealand Dialysis and Transplant Registry.

Results: The study population consisted of 460,737 people ( $n=245,573$ [53.30\%] female, mean age 47.4 years) who were Tasmanian residents aged 18 years and older and were followed for a median of 7.8 years. During the later 5 years of the study period, $86.79 \%(355,622 / 409,729)$ of Tasmanian adults were represented. The CKD cohort consisted of 56,438 people (ie, $12.25 \%$ of the study population; $53.87 \%(30,405 / 56,438)$ female, mean age 69.9 years) followed for a median of 10.4 years with 56,039 detected via eGFR and 399 people detected via documentation of KRT. Approximately half $(227,433 / 460,737,49.36 \%)$ of the study population and the majority of the CKD cohort $(41,448 / 56,438,73.44 \%)$ had an admission episode. Of the 55,366 deaths recorded in the study population, $45.10 \%(24,970 / 55,366)$ had CKD. 
Conclusions: Whole-of-population approaches to examine CKD in the community can be achieved by data linkage. Over this 14-year period, CKD affected $12.25 \%(56,438 / 460,737)$ of Tasmanian adult residents and was present in $45.10 \%(24,970 / 55,366)$ of deaths.

International Registered Report Identifier (IRRID): DERR1-10.2196/20160

(JMIR Res Protoc 2020;9(9):e20160) doi: 10.2196/20160

\section{KEYWORDS}

chronic kidney disease; dialysis; transplantation; data linkage.

\section{Introduction}

Chronic kidney disease (CKD) is a significant and growing public health burden that manifests in substantial burden of illness and premature mortality [1]. It has been named one of the "most neglected chronic diseases" [2] and has a complex interaction with other conditions, serving as a multiplier of risk in all populations. CKD significantly increases the underlying risk of premature death, hospitalization, cancer, diabetes, or major vascular events by twofold to fivefold [2]. In 2012, the total costs attributable to CKD in Australia were estimated at AUD 4.1 billion (US $\$ 3$ billion) [3]. Even early stage CKD is associated with a $50 \%$ increase in health-related expenditure; with later stages this is a sixfold increase [3]. Much of this cost is associated with the use of kidney replacement therapy (KRT; dialysis or kidney transplants).

Tasmania is the island state of Australia with a population of half a million people spread over $68,000 \mathrm{~km}^{2}$. The whole of Tasmania is classified as rural or remote with many people (37\%) living in areas of high disadvantage. The median age is 42 years, which is 5 years older than the median for Australia [4]. A significant proportion of the Tasmanian population is known to have CKD [5] with Tasmania having the highest state prevalence of CKD (highest prevalence of estimated glomerular filtration rate [eGFR] $<60 \mathrm{~mL} / \mathrm{min} / 1.73 \mathrm{~m}^{2}$ and the highest prevalence of albuminuria) [6] among non-Indigenous Australians. Conversely, Tasmania has the lowest incidence of uptake of dialysis and transplant (87 per million population [pmp] compared with 124 pmp nationally) and the lowest prevalence of dialysis (400 pmp compared with $536 \mathrm{pmp}$ nationally) $[7,8]$. Currently, the reasons for this gap between high community prevalence of CKD and low use of dialysis remain unknown. Dialysis use in all Australian states is funded by the government and therefore decisions on its use are not directly influenced by cost to the dialysis patient. Despite this model, dialysis prevalence ranges from $2956 \mathrm{pmp}$ in the Northern Territory down to $400 \mathrm{pmp}$ in Tasmania, likely influenced by local population characteristics and treatment pathways.

Linking routinely collected health data, pathology, and registry data, we examine the gap between the high community prevalence of CKD in Tasmania and the low use of dialysis. We hypothesize that many Tasmanians with CKD will (1) have a slow decline in kidney function (eGFR), (2) experience multiple comorbidities, (3) have a higher mortality rate than those without CKD, and (4) have limited access to tertiary health services depending on their rurality and socioeconomic status.

Specific aims of this data linkage study are to (1) confirm the Tasmanian burden of CKD; (2) identify geographic, gender, and age-related variation in CKD burden, progression, and use of dialysis; (3) report the mortality rate and survival of Tasmanians with CKD; (4) examine how quickly kidney function deteriorates; (5) report the general health burden of Tasmanians with CKD including diabetes, hyperlipidemia, cancer, and cardiovascular disease.

This will give us better quantitative information about the detection and progression of CKD in Tasmanians, allowing us to better understand this gap and identify health service and community needs for better management of CKD in Tasmania.

\section{Methods}

\section{Overview}

This is a retrospective cohort study using linked data from 2 pathology providers and 5 administrative health data sets, from January 1, 2004, to December 31, 2017, 14 years in total, in the Australian state of Tasmania, an area of $68,400 \mathrm{~km}^{2}$ with approximately 510,000 people [9].

\section{Data Sets for Linkage}

Ethical approval was granted by the Tasmanian Health and Medical Human Research Ethics Committee (project H0016499, approval date June 26, 2017) to access and link the following data sets (Figure 1): 
Figure 1. Linkage map.
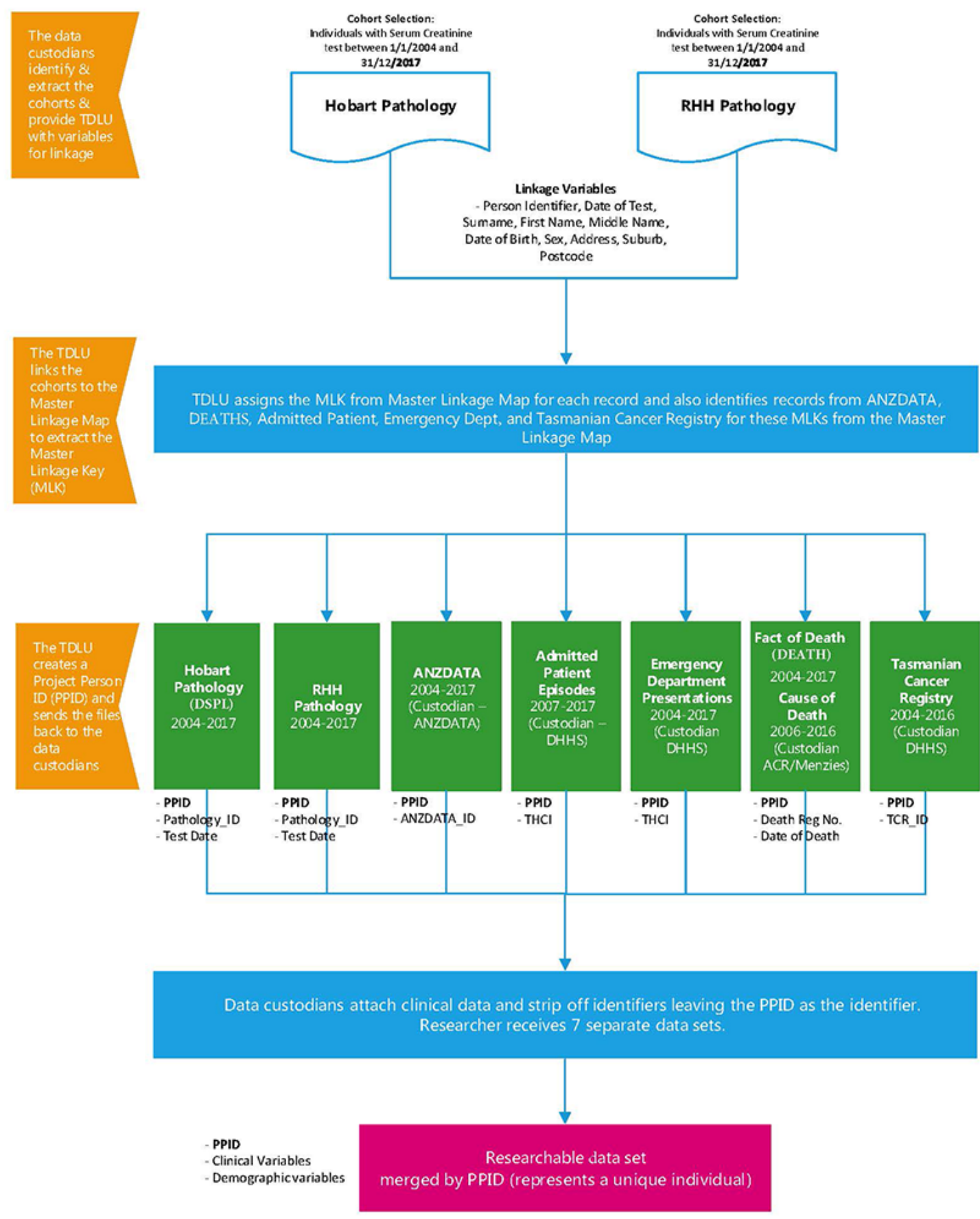

- Community and Hospital Pathology (Diagnostic Services Pty Ltd [DSPL]): Hobart Pathology, Launceston Pathology, and North-West Pathology. Pathology records provided included date, eGFR, urinary albumin-to-creatinine ratio, measures of diabetes (HbA1C), cholesterol, etc.

- Royal Hobart Hospital Pathology (RHHPATH): The largest Tasmanian public hospital pathology service provider. The data set includes pathology results for both community and hospitalized Tasmanians. Pathology records provided are the same as Community Pathology (above).

- Australia and New Zealand Dialysis and Transplant Registry (ANZDATA): records on all Tasmanians treated with dialysis or kidney transplant including the cause of kidney disease and details of their dialysis or transplant.
- Public Hospital Admitted Patient data set: date, admission, discharge, and clinical variables including primary and related diagnoses by ICD-10 code (10th edition of International Classification of Diseases and related health problems) and classification by the Australian Refined Diagnosis-Related Group for episode costing.

- Public Hospital Emergency Department Presentations: date, episode, discharge, and clinical variables including diagnoses and urgency-related groups for costing.

- Tasmanian Cancer Registry (TCR): clinical information including date, type, and stage of cancer.

- Tasmanian Fact of Death (DEATH): date of death from Births, Deaths and Marriages Tasmania; and Tasmanian Cause of Death, which presents both coded underlying and 
contributing cause of death from the Australian Coordinating Registry.

\section{Study Population}

This retrospective cohort study consists of an overall study population cohort that includes within it a CKD cohort, consisting of an eGFR cohort and a KRT cohort.

The study population consists of any adult (aged 18 years and older) who had a blood measurement of creatinine with either pathology provider, RHHPATH or DSPL, between January 1, 2004, and December 31, 2017. These providers provide the majority of community pathology services to Southern, Northern, North-West, and West of Tasmania and provide inpatient pathology services to public and private hospitals in both the south and north-west. We were unable to obtain pathology results from Launceston General Hospital or smaller Tasmanian private pathology providers. We then identified people as being Tasmanian by comparing the recorded postcode on pathology report at the date of creatinine measurement against known Tasmanian Statistical Areas Level 2 (SA2).

The eGFR cohort is identified from within the study population, where a patient has 2 recorded eGFR $<60 \mathrm{~mL} / \mathrm{min} / 1.73 \mathrm{~m}^{2}$, at least 90 days apart [10], but no more than 3 years apart. We then added to this people identified in the KRT cohort (below) to comprise the CKD cohort.

The KRT cohort is identified from within the study population using ANZDATA [7,8]. This registry was established in 1963 and maintains records of all patients with end-stage kidney disease (ESKD) receiving dialysis or transplantation in Australia and New Zealand. All patients residing in Tasmania receiving ESKD treatment and recorded in ANZDATA between January 1, 2004, and December 31, 2017, who had blood creatinine measured in the study period from the pathology providers above, are included in the KRT cohort.

\section{Data Linkage}

All linkage was performed by the Tasmanian Data Linkage Unit (TDLU), based at the Menzies Institute for Medical Research, University of Tasmania. The TDLU utilizes probabilistic record linkage using specialized data linkage software. This process attempts to link pairs of records based on the probability of them belonging to the same individual. The technique assigns scores based upon the agreement or disagreement of various linkage fields, and based upon the total score, record pairs are classified as either matches or nonmatches. The matches are recorded in the TDLU's Master Linkage Map. A series of Structured Query Language (SQL) queries are executed against the Master Linkage Map to check for incorrect links (false positives) and missed links (false negatives).

The TDLU uses a combination of linkage fields including source system identifier; first name, middle name, and surname; date of birth and date of death; gender; street address; suburb; and postcode. Blocking strategies (only matched pairs that meet certain basic criteria) are used to make the linkage process more efficient. In order for two individuals to be compared, they must have matching values for one or more blocking variables. The TDLU currently blocks on surname, street address, date of birth, derived postcode/month of birth variable. A process of deduplication is applied to data sets prior to linkage. This process identifies duplicate records within one data set using specified linkage variables.

After linkage of 2 or more data sets is completed, a process of clerical review is conducted. This ensures records that reach the score threshold, and are linked, are true matches. Only those pairs of records where there is at least one mismatch, based on either first name, surname, date of birth, date of death, or sex, between the newly linked record and the remaining records in the group are reviewed. This is known as the review pool (pool). The first stage of clerical review is to review all the groups in the pool where the linkage system has combined 3 or more groups of individuals ( 2 or more groups from the existing Master Linkage Map and the new record being linked). This situation occurs where there are 2 or more existing groups that are potential matches for the new record. In the majority of cases, the new record will become part of an existing group. There are a small number of cases where the new record contains information that allows 2 previously distinct groups to be merged into 1 group.

The second stage of the clerical review process selects groups from the pool where the new record has been linked with only 1 existing group from the Master Linkage Map. Groups are reviewed based on the scores of the new record to other records within the group. Groups with low scores are clerically reviewed first to check for false positives. Reviewers then work upward through the scores until no further false positives are identified. Following this stage of review, a further round of quality assurance is conducted to ensure the linked data satisfy a range of logic checks. These checks aim to identify and correct false positives (where 2 individuals have been incorrectly linked) and false negatives (where records for the same individual have not been linked).

On successful linkage, each individual identified was assigned a project person identifier (PPID). There were 521,320 PPIDs generated during data linkage (Table 1). 
Table 1. Linkage matrix: number of individuals identified in each data set.

\begin{tabular}{|c|c|c|c|c|c|c|c|}
\hline & $\begin{array}{l}\text { DSPL }^{a} \\
\text { pathology }\end{array}$ & $\mathrm{RHH}^{\mathrm{c}}$ pathology ${ }^{\mathrm{b}}$ & ANZDATA $^{\mathrm{b}, \mathrm{d}}$ & Admitted patient $\mathrm{e}^{\mathrm{e}}$ & $\begin{array}{l}\text { Emergency } \\
\text { department }^{b}\end{array}$ & $\begin{array}{l}\text { Tasmanian } \\
\text { Cancer } \\
\text { Registry }\end{array}$ & DEATHS $^{\mathrm{b}, \mathrm{g}}$ \\
\hline $\begin{array}{l}\text { DSPL } \\
\text { pathology }{ }^{b}\end{array}$ & $490,026^{\mathrm{h}}$ & 123,191 & 1098 & 237,122 & 315,293 & 41,764 & 53,364 \\
\hline $\begin{array}{l}\text { RHH } \\
\text { pathology }\end{array}$ & 123,191 & 154,485 & 835 & 106,827 & 125,038 & 19,065 & 26,171 \\
\hline ANZDATA $^{\text {b }}$ & 1098 & 835 & 1214 & 998 & 1060 & 184 & 480 \\
\hline $\begin{array}{l}\text { Admitted } \\
\text { patient }^{\mathrm{e}}\end{array}$ & 237,122 & 106,827 & 998 & 253,036 & 221,297 & 30,535 & 38,234 \\
\hline $\begin{array}{l}\text { Emergency } \\
\text { department }\end{array}$ & 315,293 & 125,038 & 1060 & 221,297 & 337,914 & 31,062 & 46,422 \\
\hline $\begin{array}{l}\text { Tasmanian } \\
\text { Cancer }\end{array}$ & 41,764 & 19,065 & 184 & 30,535 & 31,062 & 42,467 & 18,209 \\
\hline Registry $^{\mathrm{f}}$ & & & & & & & \\
\hline DEATHS $^{\mathrm{b}}$ & 53,364 & 26,171 & 480 & 38,234 & 46,422 & 18,209 & 55,366 \\
\hline
\end{tabular}

${ }^{a}$ DSPL: Diagnostic Services Pty Ltd.

bJanuary 1, 2004, to December 31, 2017.

${ }^{\mathrm{c}} \mathrm{RHH}$ : Royal Hobart Hospital.

dANZDATA: Australia and New Zealand Dialysis and Transplant Registry.

eJanuary 1, 2007, to December 31, 2017.

f January 1, 2004, to December 31, 2016.

${ }^{\mathrm{g}}$ DEATHS: Births, Deaths and Marriages Tasmania (Fact of Death).

${ }^{\mathrm{h}}$ Italics indicate where data sets align.

\section{Geocoding}

The TDLU, in partnership with the Menzies Institute for Medical Research, has developed a geocoding module to enable the derivation of latitude and longitude for large unit record data sets. The module uses fuzzy matching to link address data to the Geocoded National Address File. After processing, the system allocates a latitude and longitude at unit record level based on the following geographic levels:

- Address: Records coded to the Address level have been found as an exact match in the database and matched on street number, street name, suburb, state, and postcode.

- Street: Records coded at the Street level have been matched on street name and suburb, but the street number could not be found. Records have been coded to the midpoint of the street.

- Locality: Records coded at the Locality level have been matched on suburb, state, and postcode only. Records have been coded to the midpoint of the matching suburb.

- PO Box: These represent records geocoded to the Locality of the PO Box address.

- None: These records relate to addresses that could not be found in the database or Google Maps.

- Manual: These records have been found manually in Google Maps through a clerical review module and had their latitude and longitude recorded manually.
Once a latitude and longitude have been assigned, the system assigns a meshblock (defined as a geographic area) code to enable structures from the Australian Statistical Geography Standard to be derived. Statistical areas ranging from SA1 to SA4, as well as other Australian Bureau of Statistics geographic structures, can be produced using this system. Given the small population size and the potential for identification, we restricted the coding to SA2 and above (population areas of $>5000$ people).

\section{Data Cleaning}

Access, cleaning, and analysis of the linked data set were limited to 2 authors (AK and TS). In order to calculate eGFR from serum creatinine ( $\mathrm{SCr}$ ) results, each PPID requires documentation of gender (binary classification: male or female). The PPID gender was accepted if it was recorded consistently in each data set on every administrative record or if the majority of data sets had gender recorded as a specific gender. The PPID gender was left as unknown if it was recorded as unknown in all available data sets or was ambiguous between administrative data sets. If no gender could be determined, the pathology records were removed from the data set. There were 357 individuals of the total PPIDs generated during data linkage $(521,320,0.07 \%)$, with gender not recorded as male or female.

\section{Detection of CKD via Pathology (eGFR Cohort)}

SCr result was used to calculate eGFR using the Chronic Kidney Disease Epidemiology Collaboration (CKD-EPI) equation $[11,12]$. Tasmanian laboratories use enzymatic assays for 
measurement of creatinine and all results are isotope dilution mass spectrometry aligned as previously reported [13]. Stages of CKD were classified based on first eGFR according to National Kidney Foundation's Kidney Disease Outcomes Quality Initiative (KDOQI) guidelines [10] and include stage 1 (eGFR $\geq 90 \mathrm{~mL} / \mathrm{min} / 1.73 \quad \mathrm{~m}^{2}$ ), stage $2 \quad$ (eGFR=60-89 $\left.\mathrm{mL} / \mathrm{min} / 1.73 \mathrm{~m}^{2}\right)$, stage $3 \mathrm{a}\left(\mathrm{eGFR}=45-59 \mathrm{~mL} / \mathrm{min} / 1.73 \mathrm{~m}^{2}\right)$, stage $3 \mathrm{~b}\left(\mathrm{eGFR}=30-44 \mathrm{~mL} / \mathrm{min} / 1.73 \mathrm{~m}^{2}\right)$, stage $4(\mathrm{eGFR}=15-29$ $\left.\mathrm{mL} / \mathrm{min} / 1.73 \mathrm{~m}^{2}\right)$, and stage $5\left(\mathrm{eGFR}<15 \mathrm{~mL} / \mathrm{min} / 1.73 \mathrm{~m}^{2}\right.$ or treated with dialysis or a transplant).

The following CKD-EPI formulae were used:

- For females with $\mathrm{SCr} \leq 62 \mu \mathrm{mol} / \mathrm{L}$ : eGFR (mL/min/1.73 $\left.\mathrm{m}^{2}\right)=144 \times(\mathrm{SCr} \text { in } \mu \mathrm{mol} / \mathrm{L} \times 0.0113 / 0.7)^{-0.329} \times(0.993)^{\text {age in }}$ years

- For females with $\mathrm{SCr}>62 \mu \mathrm{mol} / \mathrm{L}$ : eGFR $(\mathrm{mL} / \mathrm{min} / 1.73$ $\left.\mathrm{m}^{2}\right)=144 \times(\mathrm{SCr} \text { in } \mu \mathrm{mol} / \mathrm{L} \times 0.0113 / 0.7)^{-1.209} \times(0.993)^{\mathrm{age}}$ in years

- For males with $\mathrm{SCr} \leq 80 \mu \mathrm{mol} / \mathrm{L}$ : eGFR $(\mathrm{mL} / \mathrm{min} / 1.73$ $\left.\mathrm{m}^{2}\right)=141 \times(\mathrm{SCr} \text { in } \mu \mathrm{mol} / \mathrm{L} \times 0.0113 / 0.9)^{-0.411} \times(0.993)^{\mathrm{age}}$ in years

- For males with $\mathrm{SCr}>80 \mu \mathrm{mol} / \mathrm{L}$ : eGFR $(\mathrm{mL} / \mathrm{min} / 1.73$ $\left.\mathrm{m}^{2}\right)=141 \times(\mathrm{SCr} \text { in } \mu \mathrm{mol} / \mathrm{L} \times 0.0113 / 0.9)^{-1.209} \times(0.993)^{\mathrm{age}}$ in years

The method to identify CKD consists of the following (simplified) steps:

1. Calculation of eGFR (CKD-EPI) from $\mathrm{SCr}$ for each pathology result in the study population.

2. Identification of CKD-qualifying eGFR results by filtering to include only results where eGFR is $<60 \mathrm{~mL} / \mathrm{min} / 1.73$ $\mathrm{m}^{2}$

and PPID age at result $\geq 18$ years.

3. Calculation of the number of days between qualifying eGFR results (eGFR $<60 \mathrm{~mL} / \mathrm{min} / 1.73 \mathrm{~m}^{2}$ on at least two occasions).

4. Search for a qualifying eGFR result date greater than 90 days since a previous qualifying result date, but no more than 3 years since a previous qualifying result date.

5. If a second qualifying result date was detected between 90 days and 3 years, the date of the second qualifying result was deemed to be date of diagnosis.

6. PPID was identified as Tasmanian if they had at least one Tasmanian SA2 recorded in pathology.

There were 56,039 Tasmanian PPIDs diagnosed with CKD via pathology.

\section{Identifying CKD via ANZDATA Registry (KRT Cohort)}

Although all people treated with dialysis or transplant are classified as having CKD, the pathology method described above may not identify someone who has had a successful kidney transplant and an eGFR $>60 \mathrm{~mL} / \mathrm{min} / \mathrm{m}^{2}$. Therefore the ANZDATA registry was checked for PPIDs that were not detected via the pathology detection method and had at least one treatment center within Tasmania or had received a transplant.

There were 399 Tasmanian PPIDs detected via their presence within the ANZDATA registry, due to one or more of the following: (1) PPID entry being prior to start of the pathology data set (ie, before January 1, 2004); (2) PPID having insufficient pathology results within the pathology data set prior to entry to ANZDATA; (3) PPID entry to ANZDATA prior to age 18 , and subsequently reaching the age of 18 in later years; and (4) PPID had a transplant and a Tasmanian SA2 coded pathology data after date of entry to ANZDATA.

\section{CKD Cohort}

We combined the PPIDs from both methods of detection to create a CKD cohort. In addition to PPID and sex, the following variables were extracted and added to the CKD cohort data set: Age at detection, Date at detection, Date of pathology or Date of entry to ANZDATA, Method of detection, eGFR CKD-EPI at detection, CKD Stage at detection, and SA2 at detection.

For the PPIDs that were present in ANZDATA, the following additional variables were added: Age at entry to registry, Date of entry to registry, eGFR CKD-EPI at entry to registry, Date of first dialysis, Age at first dialysis, Date of first transplant (if applicable), and Age at first transplant (if applicable)

\section{Pathology Variables Obtained}

In addition to creatinine, we obtained 25 other pathology variables (Multimedia Appendix 1). If PPIDs had an SCr test during the study period, we received all requested pathology data for them, regardless of if they had an SCr test on the same day or not.

\section{Identifying Cause of CKD and Comorbidities}

The cause of CKD was identified (where available) from the admitted patient data set using ICD-10 codes (Multimedia Appendix 2) and ANZDATA using primary renal disease code.

Comorbidities of interest were identified using ICD-10AM codes for diabetes (ICD-10AM codes E10-14), cardiovascular disease (ICD-10AM codes I00-99), and cancer (ICD-10AM codes C00-D48). Other comorbidities were determined using both the Charlson Comorbidity Index [14] and Elixhauser Comorbidity Index [15].

\section{Identifying Cause of Death}

Death data are recorded in multiple data sets including DEATH, TCR, Admitted Patient, and ANZDATA. DEATH (fact of death) was used as the primary data source, with additional death dates and cause of death added from additional data sets. Specific kidney disease-related cause of death was identified using the Australian Institute of Health and Welfare report, "Deaths from Chronic Kidney Disease" [16].

\section{Results}

\section{Study Population}

The linkage identified 521,320 people who had an SCr test in Tasmania during the 14-year study period, of whom 460,737 were determined to be Tasmanian residents (at the time of 
pathology test) aged 18 years or older and therefore became the study population.

For the 5-year period (2013-2017) there were 355,622 unique individuals aged 18 years and older included in our linked data set. As the estimated adult resident population in Tasmania was 409,729 at this time, we estimate that our study population represents approximately $86.79 \%$ of Tasmania's resident adult population during this 5-year period (Table 2).
The study population showed significant variation by age (Figure 2A and 2B), with the older population (aged 60 years and older) more likely to have a pathology test in this 5-year period $(P<.001)$.

There were 460,737 people in the study population, of which $53.30 \%(245,573 / 460,737)$ were female with a mean age of 47.4 (SD 18.3) years, having 1.1 creatinine results per person per year over the 7.8 (interquartile range [IQR] 8.3) years of follow-up (Table 3).

Table 2. The number of unique individuals and proportion of Tasmania's adult population included in the data set in the previous $1,2,3$, or 5 years (\% of estimated resident population [9] aged 18 years and older [ERP $\left.{ }^{\mathrm{a}} 18+\right]$ ).

\begin{tabular}{|c|c|c|c|c|c|c|c|c|c|}
\hline \multirow[b]{2}{*}{ Year } & \multicolumn{4}{|c|}{ Unique PPID ${ }^{\mathrm{a}}$} & \multirow{2}{*}{$\begin{array}{l}\text { Population } \\
\left(\text { ERP } 18+^{b}\right)\end{array}$} & \multicolumn{4}{|c|}{ Unique PPID $\%$ of ERP } \\
\hline & 1 year & 2 years & 3 years & 5 years & & 1 year & 2 years & 3 years & 5 years \\
\hline 2004 & 99,338 & 99,338 & 99,338 & 99,338 & 365,597 & 27.17 & 27.17 & 27.17 & 27.17 \\
\hline 2005 & 109,184 & 157,570 & 157,570 & 157,570 & 369,271 & 29.57 & 42.67 & 42.67 & 42.67 \\
\hline 2006 & 116,784 & 168,977 & 200,422 & 200,422 & 372,707 & 31.33 & 45.34 & 53.77 & 53.77 \\
\hline 2007 & 126,803 & 180,495 & 213,435 & 236,465 & 376,512 & 33.68 & 47.94 & 56.69 & 62.80 \\
\hline 2008 & 140,792 & 195,704 & 228,096 & 269,775 & 381,317 & 36.92 & 51.32 & 59.82 & 70.75 \\
\hline 2009 & 149,900 & 209,638 & 242,501 & 284,069 & 386,739 & 38.76 & 54.21 & 62.70 & 73.45 \\
\hline 2010 & 158,645 & 220,167 & 255,302 & 296,769 & 391,666 & 40.50 & 56.21 & 65.18 & 75.77 \\
\hline 2011 & 169,235 & 232,304 & 267,756 & 310,200 & 395,228 & 42.82 & 58.78 & 67.75 & 78.49 \\
\hline 2012 & 176,243 & 242,159 & 278,154 & 321,985 & 396,592 & 44.44 & 61.06 & 70.14 & 81.18 \\
\hline 2013 & 183,440 & 250,054 & 287,543 & 332,048 & 397,807 & 46.11 & 62.86 & 72.28 & 83.47 \\
\hline 2014 & 182,994 & 254,351 & 292,988 & 339,409 & 399,987 & 45.75 & 63.59 & 73.25 & 84.86 \\
\hline 2015 & 184,173 & 254,519 & 295,896 & 345,153 & 402,512 & 45.76 & 63.23 & 73.51 & 85.75 \\
\hline 2016 & 189,409 & 258,280 & 298,855 & 350,375 & 405,167 & 46.75 & 63.73 & 73.76 & 86.48 \\
\hline 2017 & 195,114 & 265,153 & 304,058 & 355,622 & 409,729 & 47.62 & 64.71 & 74.21 & 86.79 \\
\hline
\end{tabular}

${ }^{a}$ ERP: estimated resident population.

${ }^{b}$ PPID: project person identifier. 
Figure 2. (a) Male unique PPIDs by age group per year (\% of Tasmanian Population). (b) Female unique PPIDs by age group per year (\% of Tasmanian Population).

\begin{tabular}{|c|c|c|c|c|c|c|c|c|c|c|c|c|c|c|c|}
\hline 2004 & 7 & 8 & 9 & 12 & 14 & 17 & 21 & 27 & 34 & 40 & 48 & 55 & 61 & 66 & 70 \\
\hline 2005 & 7 & 9 & 11 & 13 & 15 & 18 & 22 & 29 & 37 & 45 & 52 & 59 & 63 & 67 & 71 \\
\hline 2006 & 8 & 9 & 12 & 13 & 16 & 20 & 25 & 31 & 39 & 47 & 55 & 61 & 67 & 70 & 71 \\
\hline 2007 & 8 & 10 & 12 & 14 & 17 & 22 & 27 & 34 & 41 & 50 & 57 & 64 & 69 & 72 & 75 \\
\hline 2008 & 10 & 11 & 14 & 16 & 19 & 25 & 31 & 38 & 46 & 55 & 62 & 68 & 74 & 77 & 78 \\
\hline 2009 & 10 & 12 & 14 & 17 & 20 & 27 & 32 & 40 & 48 & 58 & 64 & 69 & 76 & 76 & 77 \\
\hline 2010 & 11 & 12 & 14 & 17 & 20 & 27 & 34 & 41 & 50 & 59 & 65 & 71 & 75 & 79 & 79 \\
\hline$\succ 2011$ & 12 & 13 & 16 & 18 & 22 & 29 & 35 & 43 & 51 & 61 & 68 & 73 & 78 & 81 & 80 \\
\hline 2012 & 13 & 14 & 16 & 20 & 23 & 30 & 36 & 44 & 52 & 61 & 69 & 75 & 79 & 83 & 82 \\
\hline 2013 & 14 & 15 & 16 & 21 & 24 & 31 & 37 & 44 & 53 & 63 & 71 & 76 & 81 & 82 & 81 \\
\hline 2014 & 13 & 15 & 17 & 20 & 24 & 29 & 37 & 43 & 51 & 61 & 71 & 76 & 81 & 83 & 82 \\
\hline 2015 & 13 & 14 & 16 & 20 & 24 & 29 & 36 & 44 & 52 & 61 & 70 & 75 & 80 & 82 & 84 \\
\hline 2016 & 14 & 15 & 18 & 21 & 25 & 30 & 38 & 45 & 52 & 61 & 70 & 76 & 83 & 82 & 84 \\
\hline 2017 & 15 & 16 & 18 & 21 & 26 & 32 & 38 & 46 & 52 & 62 & 70 & 76 & 82 & 84 & 84 \\
\hline
\end{tabular}

$\mathrm{b}$

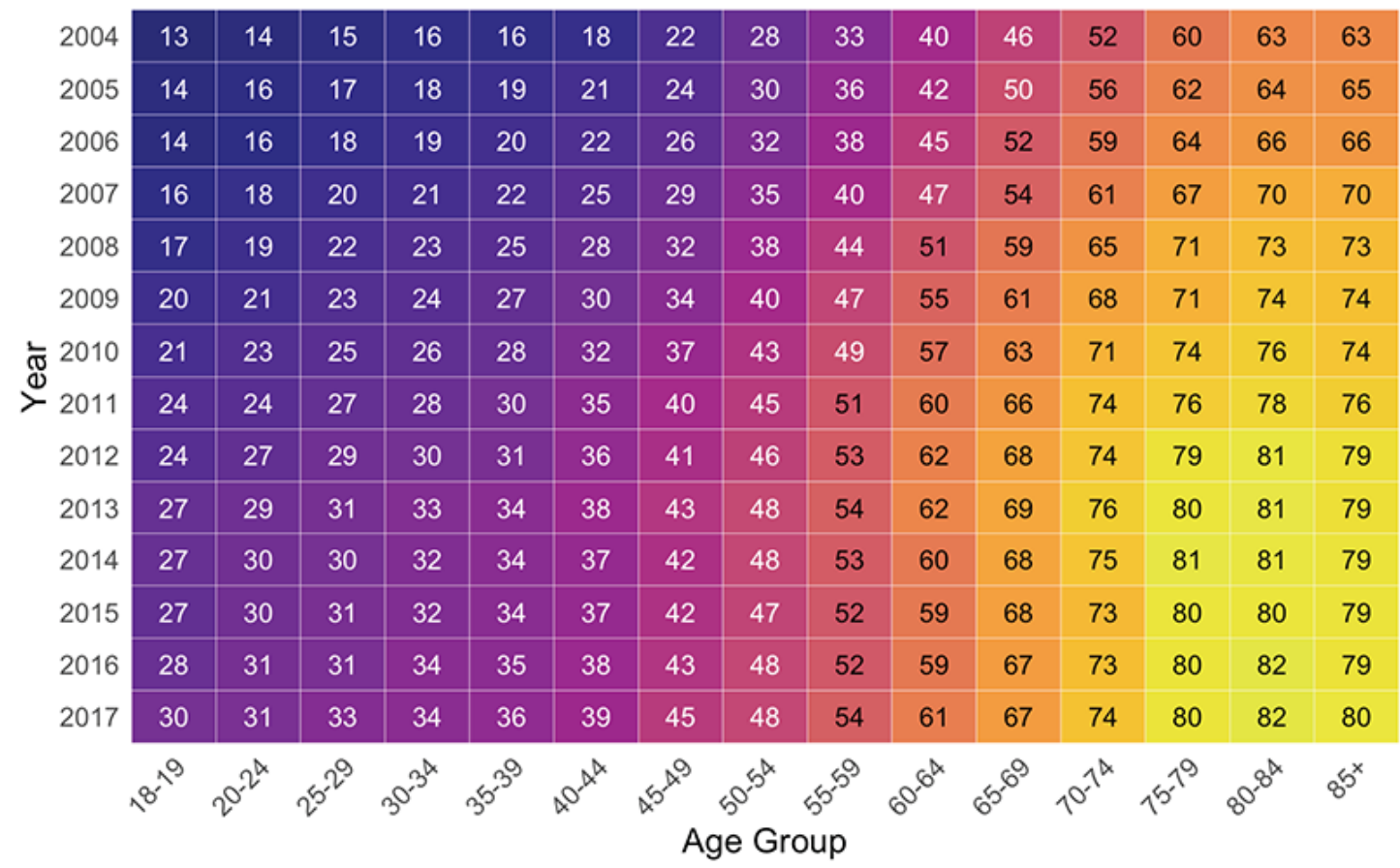


Table 3. Study demographics. ${ }^{\text {a }}$

\begin{tabular}{|c|c|c|c|c|}
\hline Demographics & Study population & $\mathrm{CKD}^{\mathrm{b}}$ cohort & Pathology & ANZDATA $^{\mathrm{c}}$ \\
\hline $\begin{array}{l}\text { Number of individuals (18 } \\
\text { years and older) }\end{array}$ & 460,737 & 56,438 & 56,039 & 399 \\
\hline $\begin{array}{l}\text { Age (years) at initial } \\
\text { eGFR }^{\mathrm{d}} \text {, mean (SD) }\end{array}$ & $47.4(18.3)$ & $69.7(11.8)$ & $69.9(11.7)$ & $51.2(15.5)$ \\
\hline Female, n/N (\%) & $245,573 / 460,737(53.30)$ & $30,405 / 56,438(53.87)$ & $30,267 / 56,039(54.01)$ & $150 / 399(37.59)$ \\
\hline $\begin{array}{l}\text { Follow-up (years), median } \\
\text { (IQR) }\end{array}$ & $7.8(8.3)$ & $10.4(6.2)$ & $10.4(6.2)$ & $9.2(9.8)$ \\
\hline $\begin{array}{l}\text { Creatinine tests per person } \\
\text { per year, median (IQR) }\end{array}$ & $1.1(2)$ & $2.4(2.8)$ & $2.4(2.8)$ & $9.9(10.6)$ \\
\hline $\begin{array}{l}\text { Age (years) at death, mean } \\
\text { (SD) }\end{array}$ & $77.4(13.9)$ & $82.8(9.7)$ & $83(9.5)$ & $64.9(12.5)$ \\
\hline Number of deaths & 55,366 & 24,970 & 24,777 & 193 \\
\hline $\begin{array}{l}\operatorname{PPID}^{\mathrm{e}}(\%) \text { with an admis- } \\
\text { sion }\end{array}$ & $227,433(49.36)$ & $41,448(73.44)$ & $41,130(73.40)$ & $318(79.70)$ \\
\hline $\begin{array}{l}\text { Total number of admis- } \\
\text { sions }\end{array}$ & $1,319,293$ & 456,337 & 387,619 & 68,718 \\
\hline $\begin{array}{l}\text { Admissions per person per } \\
\text { year, median (IQR) }\end{array}$ & $0.9(4.1)$ & $3.4(46.8)$ & $1.9(24.2)$ & $88.8(79.3)$ \\
\hline $\begin{array}{l}\text { PPID (\%) with emergency } \\
\text { department presentation }\end{array}$ & $295,943(64.23)$ & 44,801 (79.38) & $44,441(79.30)$ & $360(90.23)$ \\
\hline $\begin{array}{l}\text { Total number of emergen- } \\
\text { cy department presenta- } \\
\text { tions }\end{array}$ & $1,470,819$ & 261,603 & 258,343 & 3260 \\
\hline $\begin{array}{l}\text { Emergency department } \\
\text { presentations per person } \\
\text { per year, median (IQR) }\end{array}$ & $0.9(1.5)$ & $0.9(1.3)$ & $0.9(1.3)$ & $1.7(2)$ \\
\hline PPID (\%) with cancer & $42,099(9.14)$ & $12,975(22.99)$ & $12,906(23.03)$ & $69(17.29)$ \\
\hline $\begin{array}{l}\text { eGFR }\left(\mathrm{mL} / \mathrm{min} / 1.73 \mathrm{~m}^{2}\right) \\
\text { mean }(\mathrm{SD})\end{array}$ & $83.9(29.4)$ & $56.6(23.2)$ & $57.1(22.9)$ & $33.7(28.8)$ \\
\hline $\begin{array}{l}\mathrm{uACR}^{\mathrm{f}}(\mathrm{mg} / \mathrm{mmol}) \text {, mean } \\
(\mathrm{SD})\end{array}$ & $13.4(77)$ & $26.4(93.6)$ & $25.5(91.6)$ & $50.4(131.4)$ \\
\hline
\end{tabular}

admissions include same day and overnight.

${ }^{\mathrm{b}} \mathrm{CKD}$ : chronic kidney disease.

${ }^{\mathrm{c}}$ ANZDATA: Australia and New Zealand Dialysis and Transplant Registry.

deGFR: estimated glomerular filtration rate.

ePPID: project person identifier.

$\mathrm{f}_{\mathrm{uACR}}$ : urinary albumin-to-creatinine ratio.

\section{CKD Cohort}

The CKD cohort consisted of 56,438 people, of which $53.87 \%$ $(30,405 / 56,438)$ were female with a mean age of 69.7 (SD 11.8) years and median follow-up of 10.4 (IQR 6.2) years. Stage of CKD (when first meeting the criteria for CKD in the data set) was stage $3 \mathrm{a}$ in $73.07 \%(41,242 / 56,438)$, stage $3 \mathrm{~b}$ in $20.05 \%$ $(11,315 / 56,438)$, stage 4 in $5.21 \%(2938 / 56,438)$, and stage 5 or on KRT in $1.67 \%(943 / 56,438)$.

\section{KRT Cohort}

The KRT cohort consisted of 399 people, of which there were $37.6 \%(150 / 399)$ of female with a mean age of 51.2 (SD 15.5)

http://www.researchprotocols.org/2020/9/e20160/ years. Follow-up of the KRT cohort was for a median of 9.2 (IQR 9.8) years.

\section{Admissions and Comorbidities}

Of the 460,737 people in the study population, 227,233 (49.32\%) were in the Admitted Patient data set for a median of 1.0 (IQR 4.6) admissions per year. Of the 56,437 people in the CKD cohort, 41,448 (73.44\%) were in the admitted data set for a median of 3.4 (IQR 46.8) admissions per year (Table 3), including same-day admissions for dialysis.

\section{Deaths}

During the 14-year study period there were 55,366 Tasmanian deaths recorded, of which $24,970(45.10 \%)$ were in our CKD 
cohort. Mean age of death in our CKD cohort was 84.1 (SD 9.6) years for women and 81.3 (SD 9.6) years for men.

\section{Discussion}

\section{Overview of the Protocol}

The aim of this study was to take a whole-of-population approach to identify and follow (through data linkage) Australians who develop CKD, and identify important outcomes such as hospital admission, dialysis use, kidney transplantation, cancer, or death. We identified 460,737 individuals who had a Tasmanian residential postcode recorded at the time of pathology collection and were aged 18 years and over. Of these, 56,438 (12.25\%) met the KDIGO (Kidney Disease: Improving Global Outcomes) definition of CKD [10], making this the largest Australian CKD cohort yet reported.

The strengths of this data linkage project are the whole-of-population approach (an estimated 86.79\% [355,622/409,729] of resident adult population included), longitudinal nature allowing adequate follow-up (median follow-up of CKD cohort of 10.4 years), and a relatively contained island population with a low population turnover [9]. In addition, we use biochemical measures rather than self-report to determine prevalence of CKD, diabetes, and hyperlipidemia and link to legislated data sets including the Births, Deaths and Marriages Tasmania Fact of death and the TCR. Our estimates of CKD prevalence are consistent with our previously published 2007 data [5] and the Australian Health Survey [6].

The quality and completeness of the administrative data sets included were variable, but data conflicts and missingness were proportionally small (no sex recorded for $0.07 \%$ [357/521,320] of PPIDs generated during data linkage). While ethnicity was recorded in several data sets, concordance was $<90 \%$ and further work needs to be done to improve recognition and recording of diversity within these administrative data sets.
Notable limitations of our study include the lack of primary health data, prescribed medications including secondary prevention strategies, general information on health risk factors including actual weight, BMI, smoking history, or blood pressure control. In addition, we rely on coding practices across public health institutions for comorbidities. Private hospital admission data were not included, nor were admissions of Tasmanian residents who travel to other jurisdictions for management of these chronic conditions.

Throughout this study we have used KDIGO definitions of CKD stating that a person with 2 measurements of eGFR $<60$ $\mathrm{mL} / \mathrm{min} / 1.73 \mathrm{~m}^{2} 90$ days apart has CKD. This definition does not separate kidney disease from kidney aging and therefore does not take into account the call for age-specific thresholds to allow for an age-adapted definition [17].

We have commenced the analysis of this linked data set and hope to report our findings to the Tasmanian community within 12 months. The results will give us better quantitative information about detection and progression of CKD in Tasmanians, areas and populations of high disease prevalence, and risk factors for CKD. This will allow us to better understand this gap and identify health service and community needs, to optimize management of CKD in Tasmania through early detection and treatment.

\section{Conclusions}

We have described our methodology for the largest (retrospective) Australian CKD cohort reported to date. We will use these linked data to estimate the burden of CKD in the Tasmanian community, the progression of CKD to ESKD, the presence and influence of coexisting comorbidities and important outcomes including use of KRT (dialysis or transplant), episodes of cancer, hospitalizations, and death. We will use these data to better understand the apparent gap between high community prevalence of CKD and low use of KRT.

\section{Acknowledgments}

The authors thank the following organizations: Diagnostic Services Pty Ltd and Pathology South for provision of pathology data; the Department of Health, Tasmania for the supply of Tasmanian Public Hospital Admitted Patient and Emergency Department Presentations data; and the Registries of Births, Deaths and Marriages Tasmania, the Australian Coordinating Registry, the Coroners and the National Coronial Information System for Cause of Death Unit Record File data; the Australia and New Zealand Dialysis and Transplant Registry (ANZDATA) for provision of dialysis and transplant data; and the Tasmanian Data Linkage Unit for undertaking the linkage of these data sets. Some of the data reported here have been supplied by the Australia and New Zealand Dialysis and Transplant Registry. The interpretation and reporting of these data are the responsibility of the authors and in no way should be seen as an official policy or interpretation of the Australia and New Zealand Dialysis and Transplant Registry. This study was made possible through funding from the Tasmanian Community Fund.

\section{Conflicts of Interest}

MJ is a member of the Australia and New Zealand Dialysis and Transplant Registry (ANZDATA) Executive Committee.

\section{Multimedia Appendix 1}

Variables received from pathology services. 


\section{Multimedia Appendix 2}

ICD-10AM codes used to identify the cause of CKD.

[DOCX File, 13 KB-Multimedia Appendix 2]

\section{References}

1. GBD 2016 DiseaseInjury IncidencePrevalence Collaborators. Global, regional, and national incidence, prevalence, and years lived with disability for 328 diseases and injuries for 195 countries, 1990-2016: a systematic analysis for the Global Burden of Disease Study 2016. Lancet 2017 Sep 16;390(10100):1211-1259 [FREE Full text] [doi: 10.1016/S0140-6736(17)32154-2] [Medline: 28919117]

2. Lopez AD, Williams TN, Levin A, Tonelli M, Singh JA, Burney PGJ, et al. Remembering the forgotten non-communicable diseases. BMC Med 2014 Oct 22;12:200 [FREE Full text] [doi: 10.1186/s12916-014-0200-8] [Medline: 25604462]

3. Wyld MLR, Lee CMY, Zhuo X, White S, Shaw JE, Morton RL, et al. Cost to government and society of chronic kidney disease stage 1-5: a national cohort study. Intern Med J 2015 Jul;45(7):741-747. [doi: 10.1111/imj.12797] [Medline: 25944415]

4. ABS. Census of Population and Housing: Reflecting Australia - Stories from the Census (Contract No.: ABS 2071.0). Canberra: Australian Bureau of Statistics; 2018. URL: https://www.abs.gov.au/ausstats/abs@.nsf/mf/2071.0 [accessed 2020-08-31]

5. Jose MD, Otahal P, Kirkland G, Blizzard L. Chronic kidney disease in Tasmania. Nephrology (Carlton) 2009 Dec;14(8):743-749. [doi: 10.1111/j.1440-1797.2009.01198.x] [Medline: 20025683]

6. ABS. Australian Health Survey: Biomedical Results for Chronic Diseases, 2011-12 (Contract No.: 4364.0.55.005). Canberra: Australian Bureau of Statistics; 2013. URL: https://www.abs.gov.au/AUSSTATS/abs@.nsf/DetailsPage/4364.0.55. 0052011-12?OpenDocument [accessed 2020-08-31]

7. ANZDATA. Incidence of Renal Replacement Therapy for End Stage Kidney Disease. Adelaide: ANZDATA; 2018. URL: https://www.anzdata.org.au/wp-content/uploads/2019/09/c01 incidence 2018 ar 2019 v1.0 20191018.pdf [accessed 2020-08-31]

8. ANZDATA. Prevalence of Renal Replacement Therapy for End Stage Kidney Disease. Adelaide: ANZDATA; 2018. URL: https://www.anzdata.org.au/wp-content/uploads/2019/09/c02 prevalence 2018 ar 2019 v1.0 20191202.pdf [accessed 2020-08-31]

9. ABS. Australian Demographic Statistics. Canberra: Australian Bureau of Statistics; 2019. URL: $\underline{\text { https://www.abs.gov.au/ }}$ ausstats/abs@.nsf/mf/3101.0 [accessed 2020-08-31]

10. National KF. K/DOQI clinical practice guidelines for chronic kidney disease: evaluation, classification, and stratification. Am J Kidney Dis 2002 Feb;39(2 Suppl 1):S1-266. [Medline: 11904577]

11. Levey AS, Stevens LA, Schmid CH, Zhang YL, Castro AF, Feldman HI, et al. A new equation to estimate glomerular filtration rate. Ann Intern Med 2009 May 05;150(9):604-612 [FREE Full text] [Medline: 19414839]

12. Johnson DW, Jones GRD, Mathew TH, Ludlow MJ, Doogue MP, Jose MD, Australasian Creatinine Consensus Working Group. Chronic kidney disease and automatic reporting of estimated glomerular filtration rate: new developments and revised recommendations. Med J Aust 2012 Aug 20;197(4):224-225. [doi: 10.5694/mja11.11329] [Medline: 22900871]

13. Jose MD, Otahal P, Kirkland G, Yu R, Blizzard L. Retrospective standardisation of serum creatinine identified changes in eGFR over time. 2008 Presented at: 44th Annual Scientific Meeting of the Australian and New Zealand Society of Nephrology; 6-10 September 2008; Newcastle, Australia p. A101. [doi: 10.1111/j.1440-1797.2008.001013.x]

14. Charlson ME, Pompei P, Ales KL, MacKenzie CR. A new method of classifying prognostic comorbidity in longitudinal studies: development and validation. J Chronic Dis 1987;40(5):373-383. [doi: 10.1016/0021-9681(87)90171-8] [Medline: $\underline{3558716}$ ]

15. Elixhauser A, Steiner C, Harris DR, Coffey RM. Comorbidity measures for use with administrative data. Med Care 1998 Jan;36(1):8-27. [doi: 10.1097/00005650-199801000-00004] [Medline: 9431328]

16. AIHW. Chronic Kidney Disease (Contract No.: Cat no. CDK 16). 2019. URL: https://www.aihw.gov.au/reports/ chronic-kidney-disease/chronic-kidney-disease/contents/what-is-chronic-kidney-disease [accessed 2020-08-31]

17. Delanaye P, Jager KJ, Bökenkamp A, Christensson A, Dubourg L, Eriksen BO, et al. CKD: A Call for an Age-Adapted Definition. J Am Soc Nephrol 2019 Oct;30(10):1785-1805. [doi: 10.1681/ASN.2019030238] [Medline: $\underline{31506289]}$

\section{Abbreviations}

ANZDATA: Australia and New Zealand Dialysis and Transplant Registry

CKD: chronic kidney disease

DEATH: Births, Deaths and Marriages Tasmania Fact of Death

DSPL: Diagnostic Services Pty Ltd (Hobart, Launceston, and North West Pathology)

eGFR: estimated glomerular filtration rate

ESKD: end-stage kidney disease

PPID: project person identifier 
RHH: Royal Hobart Hospital

RHHPATH: Royal Hobart Hospital Pathology

SA2: Statistical Areas Level 2

SCr: Serum Creatinine

TCR: Tasmanian Cancer Register

TDLU: Tasmanian Data Linkage Unit

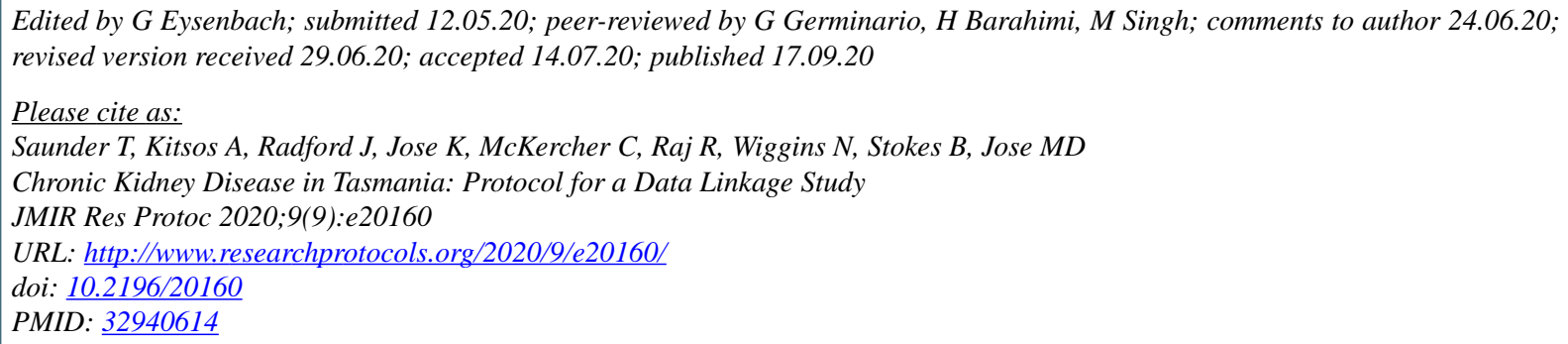

(C)Timothy Saunder, Alex Kitsos, Jan Radford, Kim Jose, Charlotte McKercher, Rajesh Raj, Nadine Wiggins, Brian Stokes, Matthew D Jose. Originally published in JMIR Research Protocols (http://www.researchprotocols.org), 17.09.2020. This is an open-access article distributed under the terms of the Creative Commons Attribution License (https://creativecommons.org/licenses/by/4.0/), which permits unrestricted use, distribution, and reproduction in any medium, provided the original work, first published in JMIR Research Protocols, is properly cited. The complete bibliographic information, a link to the original publication on http://www.researchprotocols.org, as well as this copyright and license information must be included. 